\title{
Actitudes de alumnado preadolescente ante la seguridad digital: un análisis desde la perspectiva de género
}

\section{Pre-teens students' attitudes about e-safety: an analysis from a gender perspective}

\author{
Almudena Alonso-Ferreiro \\ Universidade de Vigo. Vigo, España \\ almalonso@uvigo.es \\ Uxía Regueira \\ Universidade de Santiago de Compostela. Santiago de Compostela, España \\ uxiafernandez.regueira@usc.es \\ María-Helena Zapico-Barbeito \\ Universidade da Coruña. A Coruña, España \\ helena.zapico@udc.es
}

\begin{abstract}
Resumen
Este artículo presenta los resultados de una investigación centrada en conocer el grado de desarrollo de la competencia digital de niñas y niños de 11 y 12 años de la Comunidad Autónoma de Galicia. El foco se pone en el desarrollo de la identidad digital y la gestión de la privacidad, cuestiones de seguridad digital en el marco de referencia DigComp. Se presenta un estudio mixto que combina seis estudios de casos y la administración de una prueba de evaluación de la competencia digital (ECODIES) en la que participan, atendiendo a las variables de género y dimensión seguridad, 486 escolares. Los resultados apuntan a una discordancia entre las buenas actitudes y alta concienciación en el uso seguro de la tecnología, especialmente por parte de las niñas, y las prácticas reales en la red, mediadas por los discursos de alarma social que afectan a las formas de participación de uno y otro género.
\end{abstract}

Palabras clave: Género, seguridad digital, preadolescencia, competencia digital

\begin{abstract}
This article presents the results of an investigation focused on knowing the degree of development of the digital competence of girls and boys aged 11 and 12 in the Autonomous Community of Galicia (Spain). The focus is on the development of digital identity and privacy management, digital security issues in the DigComp framework. We present a mixed study that combines six case studies and the administration of a digital competence assessment test (ECODIES) that included participation, according to the gender and security dimension variables, of 486 schoolchildren. The results reveal a disagreement between good attitudes and high awareness in the safe use of technology, especially by girls, and real practices on the web, mediated by social alarm discourses that affect the forms of participation of both genders.
\end{abstract}

Keywords: Gender, digital safety, pre-teens, digital competence 


\section{Introducción}

En la actualidad existen evidencias que apuntan al género, junto con el capital sociocultural de las familias, como factor determinante en el uso y apropiación tecnológica de las y los jóvenes. A pesar de que recientemente se ha incrementado el interés por abordar las implicaciones del género en la competencia digital, todavía encontramos ciertas lagunas en la investigación acerca de los diferentes usos, vivencias, experiencias y actitudes mostradas por niñas y niños ante los espacios y herramientas tecnológicas (Mhlana y Krauss, 2017). En esta línea, destaca como foco de interés el análisis de las oportunidades y riesgos que propician los nuevos entornos digitales, donde las diferencias de género interfieren con la equidad en las oportunidades de desarrollo y la seguridad de las y los preadolescentes.

Es por ello que el presente trabajo incide específicamente en el estudio de una de las dimensiones de la competencia digital (CD): la seguridad en red o e-seguridad. Adoptando una perspectiva de género, el estudio tiene por objeto identificar, analizar y evaluar el desarrollo de la competencia digital de niñas y niños preadolescentes (11-12 años) de Educación Primaria de Galicia. Se trata, por otra parte, de una investigación enmarcada dentro del proyecto competitivo "Competencia digital en estudiantes de educación obligatoria: Entornos socio-familiares, procesos de apropiación y propuestas de e-inclusión (CDEPI)", financiado por el Ministerio de Economía y Competitividad (EDU2015-67975-C3-1-P) y por fondos FEDER.

Este trabajo intenta abordar cuestiones en torno al desarrollo de la dimensión seguridad por parte de las y los pre-adolescentes: ¿cómo gestionan y desarrollan su identidad digital? ¿Existen diferencias en el grado de desarrollo, en términos de actitudes y prácticas, entre un género y el otro?

Para dar respuesta a estas preguntas este artículo empieza con una revisión del estado de la cuestión de las tecnologías digitales, sus usos y relaciones mediadas por el género. Para, posteriormente, centrarse en la dimensión seguridad de la competencia digital en el marco del proyecto DigComp (Ferrari, 2013). El marco teórico se completa con la necesidad de educación desde las instituciones educativas en temas de e-seguridad y construcción de identidades digitales. A continuación se presenta el diseño de la investigación basada en un diseño mixto, con una fase cualitativa a través de estudio de casos y una fase cuantitativa en la que se emplea la prueba de evaluación ECODIDES. Tras ello se exponen los resultados a través de estadísticos descriptivos, pruebas de contrastes de hipótesis y fragmentos de los datos cualitativos. Finalmente se plantean la discusión y conclusiones.

\section{Género y tecnologías digitales}

Las niñas y niños preadolescentes se apropian de las tecnologías digitales de maneras diferentes, desarrollando prácticas y habilidades igualmente diversas que configuran su competencia digital. Así se evidencia en investigaciones que alertan de la reproducción y enraizamiento de desigualdades preexistentes en materia de género a través del universo digital, apuntando en ocasiones a la existencia de cierta brecha digital de género que afecta intensamente a mujeres y niñas (Castaño, Martín y Luis, 2011; Comisión Europea, 2018; Espinar y González, 2010; Flores-Lueg y Roig-Vila, 2017; García, Gros y Escofet, 2012; Mhlana y Krauss, 2017; Vázquez y Castaño, 2011). Estudios como el de Belloch, 
Gargallo y Suárez (2003) revelan, por ejemplo, que los adolescentes varones se encuentran en una posición más favorable en lo concerniente a disponibilidad, uso y formación en materia tecnológica, si bien las adolescentes manifestarían una actitud más positiva en relación a la integración y uso de las TIC en la escuela.

También se percibirían diferencias de género en cuanto al nivel de conocimientos informáticos -tanto reales como percibidos- en ambos géneros, así como en relación a los modos específicos en que ellas y ellos buscan información, se comunican, crean contenidos, resuelven problemas o adoptan medidas de seguridad en entornos digitales (ESSIE, 2013; Hatlevik y Christophersen, 2013; Navarro, 2009).

Diversos estudios internacionales han venido demostrando que el género tiene un impacto significativo en el nivel de habilidades digitales autopercibidas y el conocimiento de conceptos y términos relacionados con la red (Gui, 2007; Hargittai y Hinnant, 2008; Liff y Shepherd, 2005). Por una parte, encontramos que si bien las jóvenes usarían Internet casi tan frecuentemente como los jóvenes, existiendo además una escasa disparidad en cuanto a su capacidad para resolver tareas reales en línea (Hargittai, 2002; Hargittai y Shafer 2006; Van Deursen y Van Dijk, 2009), la forma en la que acceden y se apropian de ese entorno virtual es, sin embargo, más instrumental y con menos predisposición a ahondar en la exploración de detalles técnicos. Así lo constatan autores como Gui y Argentin (2011) en su investigación acerca de las habilidades digitales de adolescentes de educación secundaria, en la que corroboraron que tanto la variable género como el origen sociofamiliar generan notables desigualdades. Encontraron diferencias significativas en el desempeño digital de los y las estudiantes, de forma que las adolescentes solían ser tan hábiles como sus compañeros varones en las actividades de rutina en línea, pero experimentaban más dificultades al enfrentarse a problemas técnicos o resultados inesperados (Gui y Argentin, 2011). Otros estudios, como el coordinado por Gordo (2006), el de Garmendia, Jiménez, Casado y Mascheroni (2016) o el EU Kids Online (2014), concluían que si bien no existen disparidades relevantes asociadas al género en cuanto al nivel de conectividad a la red-dado que todas y todos navegaban de un modo igualmente intenso-, sí se producían diferencias sensibles en el tipo de uso que chicas y chicos realizaban de la red.

Por su parte, Broos (2005) encontró actitudes más negativas por parte de las niñas hacia las tecnologías digitales y la red, evidenciando una menor "ansiedad informática" por parte de los niños, que estaría asociada con un impacto positivo de la duración e intensidad de su experiencia TIC. Vekiri y Chronaki (2008) descubrieron la existencia de una gran brecha entre niños y niñas que afectaría al mayor apoyo tecnológico percibido por parte de los niños en relación a sus familias y pares, así como a una mayor autoeficacia tecnológica y creencias de valor por parte de los varones. Estos hallazgos resaltan el papel de la socialización en la brecha digital de género, advirtiendo que las niñas no poseen tanta autoconfianza ni autoeficacia digital percibida como los niños, al considerar que las tecnologías digitales están concebidas y diseñadas preferentemente para ellos. También Escofet y Rubio (2007) encontraron que los jóvenes varones mostraban un mayor grado de competencia, un mayor nivel de acceso, así como un uso diferente de las tecnologías, definido como menos funcional y cooperativo, y más lúdico e individual. Por su parte, las jóvenes solían priorizar funciones más utilitarias (procesadores de texto y otras aplicaciones informáticas) y menos lúdicas (programación y juegos), considerándose además menos habilidosas que sus compañeros ante los ordenadores y demostrando una mayor inseguridad y una actitud menos imperativa o de dominio informático que los 
chicos. Esta clase de actitudes y autopercepciones incidirían sin duda en las capacidades $\mathrm{y}$ actitudes hacia el uso de las TIC en el hogar y en la escuela.

Así mismo, un estudio realizado recientemente en escuelas de 31 países europeos (ESSIE, 2013) revelaría una preferencia ligeramente superior hacia los ordenadores por parte de los niños que de las niñas, si bien no se ahonda en las razones que subyacen tras estos resultados. Por su parte, Volman, Van Eck, Heemskerk y Kuiper (2005) constataron que, aún siendo similar el nivel de uso que niñas y niños realizan de esas tecnologías en la escuela, las primeras centran más su empleo en el envío de correos electrónicos y su participación en redes sociales, mientras los segundos juegan más a videojuegos. Esta preferencia de las niñas por servicios y plataformas que posibilitan establecer relaciones y favorecen la socialización y la de los niños por espacios de juego y servicios lúdicos ha sido destacada en múltiples investigaciones (Byrne, Kardefekt-Winther, Livingstone y Stoilova, 2016; Fernández-Montalvo, Peñalva, y Irazabal, 2015; Garmendia et al., 2016). Autores como Toft-Nielsen (2016) analizan también las complejas conexiones entre género, tecnología e identidad, que se entrecruzan, construyen y negocian en diferentes contextos sociales, demostrando que los juegos digitales se integran en un marco cultural en modo alguno neutral en cuanto al género, expresando formas de dominación masculina. Otros estudios como el de Samuelsson (2010) muestran que el uso de las TIC por parte de niños y niñas difiere tanto en términos cualitativos como cuantitativos. Estas diferencias de género en el campo digital se van agudizando además a medida que nos acercamos a la educación secundaria.

Si nos centramos en el campo de las redes sociales, autoras como Alonso-Ruido et al. (2015) han constatado que si bien estas son utilizadas por los y las adolescentes con una frecuencia muy similar, existen sin embargo diferencias significativas en función del género que afectan, por ejemplo, al volumen de amistades que poseen las chicas en redes como Twitter o Instagram, muy superior al de sus compañeros, así como a los discursos, prácticas letradas digitales e identidades construidas por ambos sexos (Pérez-Sinusía y Cassany, 2018). También se evidenció la escasa supervisión general ejercida por las familias en relación al acceso y uso que sus hijas e hijos de secundaria hacen de las redes sociales.

El estudio sobre la desigualdad de género y sexismo en las redes sociales de Estébanez y Vázquez (2013) concluía además que las jóvenes suelen hablar con mayor frecuencia de sus sentimientos y frustraciones a través de las redes sociales, compartiendo y exponiendo su intimidad en la red con mucha mayor intensidad que los jóvenes. En ese sentido, resulta especialmente significativo el caso de las niñas y jóvenes blogueras documentado por investigadoras como Dmitrow-Devold (2011, 2017), quien analiza la evolución de las prácticas digitales de las adolescentes en el marco de un espacio que define como competitivo, centrado en el cuerpo femenino, fuertemente comercializado y asociado a la cultura de las celebridades. Los significados vinculados a la etiqueta de identidad blogger se asocian a representaciones públicas de las niñas "homogéneamente superficiales, enmarcándolas como populares pero insignificantes, como innovadoras pero irresponsables, como inteligentes pero vulnerables" (Dmitrow-Devold, 2011, p.72). Estas prácticas digitales proporcionan pistas acerca de la construcción de nuevas identidades femeninas on-line y de nuevas formas de participación contemporánea de las niñas en los medios digitales, en un complejo equilibrio entre competencia digital, exposición pública y nuevas subjetividades de género, no exentas de estereotipos sexistas. 
Nos encontramos también con una sub-representación femenina en entornos digitales como YouTube, una carencia de referentes para las niñas y una presencia insuficiente y desequilibrada de las mujeres, que son sometidas además frecuentemente a respuestas más negativas, duras y hostiles en este y otros medios que sus homólogos masculinos (Wotanis y McMillan, 2014). La investigación evidencia la necesidad de seguir identificando estrategias e intervenciones que fomenten el liderazgo femenino y la inclusión de voces diversas en estos ámbitos, desde una perspectiva decididamente igualitaria y feminista.

Abundan igualmente los ejemplos de uso intenso y frecuente de tecnologías efímeras como Snapchat, Frankly o Wickr, desde las que se construyen discursos fuertemente influyentes en las subjetividades juveniles de las y los adolescentes, salpicadas por prácticas que vulneran, en ocasiones, pilares básicos de la seguridad digital, como el sexting o el ciberacoso (Charteris, Gregory y Masters, 2018), y a las que conviene prestar también necesaria atención desde una perspectiva socioeducativa. No podemos obviar que, como aseguran Gelpi, Pascoll y Egorov (2019), "las redes sociales online y otros espacios virtuales han producido cambios en la normatividad de las conductas sexuales, ampliando las representaciones culturales de sexualidad" (p.76) en un proceso sin retorno.

Ante la situación hasta ahora dibujada, coincidimos con Bonder (2008) al incidir en la necesidad de impulsar planteamientos y procesos formativos problematizadores desde una perspectiva de género que arrojen luz "sobre los conflictos y las resistencias que necesariamente se activan al integrar una concepción que subvierte supuestos y prácticas patriarcales de viejo y nuevo cuño" (p. 928), sumergiéndonos desde un enfoque feminista en las prácticas digitales cotidianas de la juventud. Como señala esta misma autora, a pesar de que el consumo de tecnología digital está extraordinariamente extendido entre las y los jóvenes, sus hábitos, actitudes y capacidades de apropiación son muy diversas en función del entorno social, el capital cultural y el género. Otras investigadoras como Herring y Martinson (2004) ponen además el foco en que esta última variable fue introducida en los estudios acerca de las TIC con carácter relativamente reciente y tardío, demostrándose que los nuevos entornos y herramientas, lejos de generalizar la imprescindible superación de los estereotipos sexistas, han venido a reproducir las jerarquías de género (Bonder, 2008).

Esta brecha digital de género afecta también de modo especial a la forma en que las preadolescentes y jóvenes se interesan o involucran en estudios relacionados con tecnologías, evidenciándose una excluyente segregación por sexos y un abandono prematuro de su interés hacia materias y/o carreras tecnológicas, científico-técnicas, ingenierías y matemáticas (STEM) ya durante la etapa de educación secundaria (Beyer, 2016; Gabay-Egozi et al., 2015; Sadler et al., 2012; Zagami et al., 2015). En ese sentido, estudios como los de Mann y Diprete (2013), McLachlan, Craig y Coldwell (2010) o Unfried et al. (2015) ponen el foco en la escasa confianza femenina en el campo tecnológico, en contraste con una actitud masculina reforzada y más dominante en ese ámbito específico, que vendría a extenderse hasta la educación superior y a agudizarse ante la carencia de referentes y la subrepresentación femenina en ese entorno (Wisniewski, 2017). Advirtiendo de los riesgos inherentes a esa dominación masculina en el campo tecnológico y a la proliferación de estereotipos de género, organismos como el Parlamento Europeo (2016) instan a los Estados miembros a que aprovechen plenamente el potencial que encierran la sociedad de la información, las tecnologías digitales, la red y los espacios virtuales a la hora de fomentar el empoderamiento de la 
mujer y sus derechos y libertades, defendiendo la igualdad de género y el empoderamiento de la mujer en la era digital. Solicitan además el establecimiento de acciones estratégicas encaminadas a la promoción de la igualdad de género y el uso de las tecnologías como herramientas de lucha decidida contra la discriminación por razón de sexo y el logro de la inclusión digital real de mujeres y niñas. Así mismo, colectivos feministas apuntan a que las estrategias de enseñanza en áreas STEM se han venido "centrando en los hombres y no tienen en cuenta los diferentes estilos de aprendizaje de hombres y mujeres" (Comisión Europea, 2018, p.18).

\section{Competencia Digital: dimensión seguridad}

En este contexto, la formación y desarrollo de la competencia digital, como uno de los aprendizajes clave del siglo XXI, se vuelve fundamental para la supresión de estas brechas. En el proyecto CDEPI se toma como referencia la definición de Competencia Digital del Proyecto DigComp (2013, 2016), marco de referencia europea, que incluye dominios de aprendizaje, herramientas, áreas competenciales, modos y propósitos, y la define como

el conjunto de conocimientos, habilidades, actitudes, estrategias y valores que son requeridos cuando se usan las TIC y los medios digitales para desempeñar tareas, resolver problemas, comunicarse, gestionar información, colaborar, crear y compartir contenido y crear conocimiento, de forma efectiva, eficiente, apropiada, crítica, creativa, autónoma, flexible, ética y reflexiva, para el trabajo, el ocio, la participación, el aprendizaje, la socialización, el consumo y el empoderamiento. (Ferrari, 2012, p. 30)

La competencia digital refiere a un constructo en constante cambio, en línea con las transformaciones socio-tecnológicas que se suceden en el momento histórico actual. Es un concepto dinámico, en evolución y expansión, que implica desarrollar el razonamiento crítico en el dominio de diferentes lenguajes específicos en el uso de las tecnologías digitales (Alonso-Ferreiro, 2016).

DigComp (2016) establece cinco áreas competenciales que se interrelacionan, complementan e interactúan: información y alfabetización informacional, comunicación y colaboración, creación de contenidos digitales, seguridad y resolución de problemas.

Una de las áreas que despierta mayor preocupación a familias e instituciones que trabajan con menores es la dimensión seguridad, como evidencia la extensa investigación sobre el tema (Annansingh y Veli, 2016; Byrne, Kardefelt-Winther, Livingstone y Stoilova, 2015; Fernández-Montalvo, Peñalva, y Irazabal, 2015; Garmendia, Jiménez, Casado y Mascheroni, 2016; Livingstone, 2008, 2014) y las múltiples iniciativas que inciden en el uso seguro de la red.

El Proyecto DigComp 2.1 (Carretero, Vuorikari, y Punie, 2017) apunta cuatro competencias que configuran la dimensión seguridad:

- Protección de dispositivos. Supone crear soluciones para resolver problemas complejos y habilidades para gestionar los riesgos y amenazas en entornos digitales, actuando de forma segura y confiada protegiendo la privacidad.

- Protección de la privacidad y de los datos personales en entornos digitales. Comprender cómo se usan y comparten los datos de identificación e información 
personal, a la vez que se protege la privacidad, y entender cómo funcionan las políticas de privacidad de datos personales de las plataformas y redes sociales. Implica un uso responsable y habilidades para crear y gestionar la identidad digital.

- Protección de la salud y bienestar. Competencias que implican conocer y evitar los riesgos y amenazas para un bienestar psicológico y físico. Implica poder protegerse a uno mismo y a otros de posibles peligros de los entornos digitales, como puede ser el acoso en la red (ciberbullying), la práctica que más sufrimiento ocasiona a niñas y niños de entre 9 y 12 años (Garmendia et al., 2016). Además de actitudes y conciencia sobre las posibilidades de las tecnologías para el bienestar y la inclusión social.

- Protección del entorno. Refiere a la conciencia y actitudes hacia el impacto ambiental que generan los medios digitales en su consumo y uso.

El uso seguro de las tecnologías digitales e Internet refiere a un uso inteligente, crítico y reflexivo de las mismas. Implica aprovechar con eficacia y utilizar con seguridad los medios, lo que supone enfrentar las oportunidades y riesgos que supone la expresión de la propia identidad digital. Cuestiones relativas a la privacidad y a la compleja tarea de gestionar lo público y lo privado en los espacios online.

Son muchas las iniciativas, programas y planes que ponen el foco en la educación de la ciudadanía en un uso seguro y saludable de las tecnologías digitales. A continuación se exponen aquellas de mayor difusión y alcance en los centros educativos, así como las propuestas que emergen del Ministerio de Educación.

La iniciativa PantallasAmigas ${ }^{1}$, en activo desde 2004, tiene el objetivo de sensibilizar en el uso responsable, seguro y saludable de Internet y las tecnologías digitales, así como prevenir situaciones de riesgo en la red. Su labor se centra en desarrollar la dimensión seguridad de la competencia digital, formando en conocimientos, habilidades y actitudes para una ciudadanía digital crítica y responsable. Cuenta con una amplia oferta de recursos e información sobre los riesgos de internet: ciberviolencia de género, ciberbullying, grooming, sexting, privacidad, sextorsión, ciberdelitos, robo de identidad, revenge porn y tecnoadicción. Pone además a disposición de la comunidad educativa recursos y materiales didácticos y educativos para la prevención contra la distribución de imágenes no consentidas, contra discursos de odio en favor del respeto a la diversidad, cuestiones de netiqueta, decálogos de uso seguro, y guías de prevención para madres, padres y personal docente.

IS4K (Internet Segura for Kids ${ }^{2}$ ) es, como se indica en su web, el Centro de Seguridad en Internet para menores de edad en España, cuyo objetivo se centra en la promoción del uso responsable y seguro de las tecnologías digitales e Internet entre las y los menores. Entre sus tareas destaca mantener informada y actualizada a la comunidad educativa y desarrollar campañas, programas e iniciativas de sensibilización. Para ello dispone de una Web dinámica con un espacio destinado a familias, con recursos para ayudar a la labor parental en el día a día; así como un espacio para educadores con propuestas didáctica centradas en el uso seguro y responsable de Internet o contenido de ayuda para los responsables TIC de los centros educativos.

\footnotetext{
${ }^{1}$ https://www.pantallasamigas.net/

${ }^{2}$ https://www.is4k.es/
} 
El Plan Navega con Rumbo ${ }^{3}$ es una iniciativa dirigida directamente a las y los escolares con el fin de que desarrollen las competencias para participar de forma segura, activa y saludable en la red. Se trata de un programa enmarcado en el Proyecto Abalar (política TIC educativa de Galicia). Ofrece guías de navegación para el alumnado, profesorado y familias, que completan las acciones del programa centrado en visitas a los centros educativos.

A este respecto, desde el Gobierno de España, también se desarrollan iniciativas en torno al uso seguro de la red. Desde el Instituto Nacional de Tecnologías de la Comunicación (INTECO) se abordan las guías legales en torno a las Redes sociales, menores de edad y privacidad en la red (INTECO, 2010). En este documento se enuncian los derechos a la protección de datos de carácter personal y a la intimidad y protección de privacidad de la propia imagen, a los que se renuncia en parte con la participación y exposición en redes sociales. Este informe evidencia la falta de conciencia de los menores sobre la accesibilidad de los datos que publican, con valor para el mercado; ya que es común que las condiciones de registro en estas redes sean aceptadas, lo que supone una cesión de derechos de los contenidos que se alojan en las plataformas. Se cierra con recomendaciones INTECO para un disfrute seguro de Internet, así como con medidas de recomendación de comportamiento en la red para los menores.

Más recientemente desde el Ministerio de Educación y Formación Profesional, concretamente a través del Instituto Nacional de Tecnologías Educativas y Formación del Profesorado $\left(\mathrm{INTEF}^{4}\right)$, se han lanzado iniciativas para la formación del profesorado en ejercicio en un uso seguro de la red. Una de las líneas de actuación principales de este Instituto se centra en la creación y desarrollo de cursos en línea para la transformación digital de la educación. Entre las experiencias de aprendizaje que oferta destacan tres tipos de enfoques diferenciados: 1) NOOC (Nano Open Online Course), experiencias de aprendizaje abierto colaborativo que se centran en un objetivo muy concreto del Marco Común de Competencia Digital Docente (INTEF, 2017). Con este enfoque se llevaron a cabo en el último mes varias actividades de formación centradas en la dimensión seguridad: Ciberacoso, Respeto digital y protección de datos personales, Privacidad en la red, Cuidado de la identidad digital (Sexting y otras prácticas de riesgo), Adicción a la tecnología, Alerta virus, y Estafas y fraudes en la red; lo que indica una preocupación y tendencia por trabajar esta temática. 2) EduPills, se trata de una aplicación móvil para el aprendizaje autónomo centrado en píldoras educativas sobre las cinco dimensiones de la competencia digital. 3) MOOC (Masive Open Online Course), son cursos de formación online abiertos y colaborativos, una nueva modalidad de formación con propuestas orientadas a la formación del profesorado en múltiples temáticas, entre ellas la competencia digital docente.

Todas estas iniciativas ponen de manifiesto la relevancia y actualidad de la complejidad de la seguridad en la red, una de las dimensiones de la competencia digital que pone el foco en cuestiones de privacidad, como la gestión de contraseñas, y de identidad digital.

Las investigaciones previas sobre e-seguridad revelan la concienciación y buenas actitudes hacia la seguridad, con una percepción de competencia mayor en los sujetos varones, a la vez que evidencian el bajo desempeño en prácticas relacionadas con el uso seguro y responsable en Internet (Annansingh y Veli, 2016; ESSIE, 2013; Gallego-

\footnotetext{
${ }^{3}$ https://www.edu.xunta.es/navegaconrumbo/presentacion.html

${ }^{4}$ https://intef.es/
} 
Arrufat, Torres-Hernández, y Pessoa, 2019). A este respecto ESSIE (2013), una investigación a gran escala previamente mencionada, revela que el alumnado español con una percepción general moderada de su competencia digital, se percibe como altamente competente en cuestiones de seguridad, con valores por encima de la media europea.

Las y los jóvenes parecen tener conocimientos sobre situaciones de riesgo y conciencia sobre prácticas adecuadas como no dar información personal, promover la protección y cuidado de la imagen virtual propia y de los otros, y mostrar un comportamiento apropiado en entornos digitales, como apuntan los hallazgos de las investigaciones de Gallego-Arrufat et al. (2019) y Alonso-Ferreiro (2016), con alumnado universitario y de enseñanzas básicas, respectivamente.

El uso de contraseñas seguras o la aplicación de protocolos para cambiarlas, así como mantener en privado los propios nombres de usuario/a, no son prácticas comunes entre las y los más jóvenes (Byrne et al., 2015; Gallego-Arrufat et al., 2019), que además comparten información y contenido de forma inapropiada con frecuencia, lo que supone dificultades para conocer cómo gestionar la privacidad online y la identidad digital. Dadas las dificultades de gestión de la privacidad en la red, para las y los preadolescentes y adolescentes es una prioridad cambiar el funcionamiento de la configuración de privacidad, práctica que sólo un cuarto de niñas y $15 \%$ de niños dicen saber realizar (Garmendia et al., 2015), además de bloquear publicidad no deseada o correos basura y eliminar el SPAM y las cadenas de mensajes, intrusiones a su privacidad (Garmendia et al., 2015; Livingstone, 2008).

Una de las prácticas entre las que hay cierta contradicción en función de las investigaciones es la referida a las relaciones con extraños en la red. Una práctica que implica un equilibrio entre el riesgo (con respecto a la privacidad, la incomprensión, el abuso) y la oportunidad, ya que permite la relación con otras personas, con diversas experiencias y situaciones (Ito et al., 2009; Livingstone, Mascheroni y Staksrud, 2015), así como relaciones basadas en la cultura participativa (Jenkins, 2009). La investigación de Livingstone (2008) revela que, a pesar del pánico generado sobre los medios acerca del peligro de conectar con extraños, para las y los adolescentes es más preocupante que su información visible llegue a personas consideradas por ellas y ellos "inapropiadas", especialmente los progenitores/as. Esta investigación revela que prefieren perfiles públicos para sus amistades pero privados para las madres y padres. La investigación de Fernández-Montalvo et al. (2015) apunta en la misma dirección, ya que los hallazgos reflejan que añadir a desconocidos en las redes y quedar con estas personas es un comportamiento de riesgo común entre los y las jóvenes; con mayor propensión entre los sujetos masculinos. Mientras que investigaciones como la de Byrne et al. (2015) y la de Garmendia et al. (2016), aunque mantienen la tendencia de mayor propensión entre el género masculino, ponen de manifiesto que se trata de una práctica minoritaria, principalmente realizada por mensajería instantánea y redes sociales. La respuesta mayoritaria de preadolescentes de entre 11 y 12 años refiere a aceptar peticiones de amistad solo de personas conocidas (74\%).

Livingstone (2008) apunta a las limitaciones que supone la concepción binaria de las redes sociales sobre los "amigos", pues dan forma a la privacidad online, lo que de alguna forma socava las potencialidades de estas redes. El concepto de privacidad limita las posibilidades de expresión de la propia personalidad que ofrecen las redes sociales, donde algunos jóvenes expresan una noción de identidad vivida a través de relaciones auténticas en la red (Livingstone, 2008). La mayoría de los menores de entre 9 y 12 años mantienen 
un perfil privado ( $45 \%)$, mientras que un tercio de las adolescentes $(33 \%)$ y un cuarto en el caso de ellos (26\%) lo tiene parcialmente privado de forma que los amigos pueden verlo (Garmendia et al., 2016). En estos perfiles es común que los menores publiquen una foto de su propio rostro e información personal como apellidos, número de teléfono o su escuela (Fernández-Montalvo et al., 2015), comportamientos alejados de una buena gestión de la identidad digital, pero que reflejan preocupación por la privacidad (Livingstone, 2008), pues suponen enfrentar la decisión de qué compartir con los otros y qué mantener en la intimidad.

Otra práctica habitual es la mentira acerca de la edad o la apariencia física (FernándezMontalvo et al., 2015; Garmendia et al., 2016), con porcentajes que oscilan en función de la investigación entre el $25 \%$ y el $46 \%$. Así como, en porcentajes muy bajos, se producen situaciones de ciberbullying, que son las más dañinas para la salud de niñas y niños (Byrne et al., 2015).

La revisión de los antecedentes realizada pone de manifiesto la interconexión de las oportunidades y riesgos de la red (Livingstone, 2008), con espacios para expresarse, socializar, aprender o comprometerse con la comunidad, con las problemáticas que de esa participación social, activa y comprometida, puedan derivarse. En este contexto se evidencia la necesidad de una competencia digital amplia para gestionar la propia identidad digital y contar con formación y herramientas para beneficiarse de las oportunidades de la red y enfrentar los riesgos que puedan aparecer, que no necesariamente suponen un daño al menor.

A este respecto el propio currículo de Educación Primaria para la Comunidad Autónoma de Galicia (Decreto 105/2014) establece siete competencias clave entre las que destaca la competencia digital, para cuya definición toma como marco de referencia las cinco dimensiones del proyecto DigComp. La dimensión seguridad se reduce, en el texto curricular, a los riesgos asociados al uso de tecnologías digitales y estrategias para evitarlos, reforzando el discurso del miedo en el uso de estos medios. En el desarrollo del currículo, esta dimensión aparece de forma puntual en contenidos referidos al cuidado de recursos informáticos, a la precaución en los tiempos de uso de las TIC y posibles adicciones, y a conductas responsables en el uso de estas tecnologías, en términos de autonomía, autocontrol, seguridad y sentido ético (Alonso-Ferreiro, 2016). Los contenidos relacionados con la gestión y cuidado de la identidad digital se ubican en el área de Educación para la ciudadanía y los derechos humanos, que solo se imparte en $5^{\circ}$ o $6^{\circ}$ de educación primaria, con un horario limitado (dos sesiones semanales). Este análisis evidencia que, a pesar de la preocupación sobre el tema, es necesaria una mayor y mejor formación (Annansingh y Veli, 2016) para el uso seguro y responsable de Internet. La responsabilidad en la formación en torno a una ciudadanía digital crítica, con competencias para gestionar de forma eficaz su identidad digital en la sociedad actual aparece diluida en el currículo.

\section{Educación vs. Miedo. La necesidad de intervenir desde la educación}

El desarrollo tecnológico y sus consecuentes cambios en la comunicación y el modo en el cual las y los jóvenes se relacionan, se ha acompañado de un pánico mediático que amplifica la ansiedad pública vinculada a las redes sociales (Livingstone, 2008). La idea de que las y los jóvenes afrontan una serie de riesgos en Internet, se ha convertido en un tema de debate frecuente, tanto en el contexto popular como en la academia, lo que hace 
que las historias de abuso, adicción y descontrol ocupen gran parte de las preocupaciones de los adultos, de la prensa y de las campañas políticas (Marciales y Cabra, 2011).

De acuerdo con Buckingham (2002) esta expresión de pánico puede figurarse como irracional e incontrolable, implicando una especie de falsa conciencia creada por el periodismo sensacionalista; pero estas preocupaciones se derivan de miedos preexistentes y de temores que siempre han estado presentes en el cuidado que los padres y madres proporcionan a sus hijos e hijas. Por consiguiente, se reconoce como una reacción a los cambios producidos por los propios medios, en particular por Internet, un medio de difícil control que ha facilitado el acceso a diferentes expresiones de violencia a una edad cada vez más temprana (Marciales y Cabra, 2011). Si bien Internet abre una nueva ventana a los peligros a los que se exponían las personas en el mundo físico, trasladando la preocupación de familias y otras figuras a este espacio; estos se articulan ahora a través de una nueva expresión e impacto ante el cual una ciudadanía caracterizada por una brecha de acceso, uso y apropiación, se siente indefensa.

En este contexto, el riesgo del impacto de las tecnologías se constituye como un eje para repensar la actuación en todos los planos de las sociedades. El énfasis en el riesgo implica una reducción de la seguridad a la problematización de la tecnología; la cual se legitima mediante el uso de voces autorizadas, como las de los académicos/as u otros expertos/as (Korkmazer, De Ridder y Van Bauwel, 2019) que profundizan en fenómenos ligados a los riesgos y amenazas en la red; tales como el ciberbullying, ciberstalking, cibergrooming, pornografía, sexting, radicalización y otras formas de violencia.

A este respecto, Ferrés y Piscitelli (2012) aluden a una visión reduccionista de la competencia digital por parte de la escuela, centrada en los aspectos técnicos y desatendiendo la formación del espíritu crítico. Lo cual conlleva que el peso del discurso del miedo recaiga en las familias y otros agentes externos a la escuela vinculados a la perspectiva jurídica (del delito) como los cuerpos de seguridad del Estado.

El uso creativo y seguro de las tecnologías está ligado, por consiguiente, al capital sociocultural, económico y tecnológico de las familias (Vazquez-Calvo y Regueira, 2019); ampliando la brecha en el dominio de las que algunas autoras y autores denominan tecnologías del empoderamiento (Reig-Hernández, 2012; Sánchez-Valle, Frutos-Torres, Vázquez-Barrio, 2017).

Algunas familias, condicionadas por el discurso del miedo, se sienten indefensas para proteger a sus hijas e hijos; especialmente en aquellos casos donde existe una brecha técnica dentro de la misma. Se sienten incapaces de regular el tiempo dedicado a las TIC, uno de los riesgos que perciben con mayor preocupación; el acceso a contenidos no adecuados o el contacto con desconocidos; y demandan a las escuelas estrategias para poder actuar ante situaciones de riesgo (Sánchez-Antolín, Andrés Viloria, Paredes-Labra, 2018). Este miedo se traduce de forma frecuente en el control parental invasivo y la limitación de tiempo, espacios y uso de los dispositivos, incluso la privación total, sin responder a un criterio o considerar las oportunidades de un uso seguro de la tecnología.

En un contexto caracterizado por la brecha digital, la popularización del discurso del miedo y la alarma mediática, se le demanda a las y los jóvenes una extrema precaución en la exposición a los riesgos de la red. La evidencia de que las habilidades tecnológicas ligadas al manejo de dispositivos que puedan reunir las y los jóvenes, se aleja de la capacidad de comprender críticamente el contexto mediático en el cual se circunscriben (Sanchez-Valle, Frutos-Torres, Vazquez-Barrio, 2017), manifiesta que estas/os se 
encuentran desprovistos de mecanismos de actuación ante tales demandas. Se exige una responsabilidad preventiva que se aleja de la educación en la adquisición de competencias de seguridad digital, en favor de la limitación de su actividad.

Este discurso se agrava en aquellas personas consideradas de mayor potencial de riesgo: las niñas y jóvenes, que reciben un discurso más responsabilizador y restrictivo que el de los niños. La red como parte del entramado social reproduce las estructuras de poder (Ficoseco, 2016); de modo que la sociedad responsabiliza a las jóvenes, bajo una lógica heteropatriarcal, de los riesgos que les reserva la red por su condición de género. Una categorización de género en la que las niñas se incluyen ampliamente en el debate, desde una perspectiva paternalista que restringe su participación; y los niños y sus experiencias digitales a menudo se excluyen o se relegan a un segundo plano (Korkmazer, De Ridder y Van Bauwel, 2019). Un discurso que victimiza a las jóvenes y, a su vez, las responsabiliza de los potenciales riesgos a los que se exponen en la red; de forma que demanda en ellas una restricción mayor en la configuración de su identidad digital y los vínculos e interacciones que genera en esta; obviando una responsabilidad comunitaria.

\section{Metodología}

La investigación realizada busca conocer, identificar, analizar y evaluar el grado de competencia digital de preadolescentes, de entre 11 y 12 años, que cursan $6^{\circ}$ de Educación Primaria, en la Comunidad Autónoma de Galicia. En concreto este artículo se centra en el desempeño en la dimensión seguridad de dicha competencia, atendiendo a cuestiones relativas a la gestión de la identidad digital de niñas y niños; analizar usos, espacios y formas de participación en función del género e identificar discursos y prácticas de riesgo y preocupación en función del dicha variable.

Se plantea un diseño mixto, combinando tanto métodos cuantitativos como métodos cualitativos en el marco de la misma investigación, de forma que permita una comprensión más amplia, y a la vez profunda, del problema de investigación (Creswell y Plano Clark, 2007). El diseño consta de una primera fase basada en estudio de casos y una segunda centrada en una prueba de evaluación.

\subsection{Estudio de casos}

En la primera fase, cualitativa, se seleccionaron seis sujetos, que conformaron el estudio de caso múltiple con enfoque etnográfico (Simons, 2011). Los niños y niñas participantes y sus madres, padres o tutores/as legales según el caso, recibieron un documento con los objetivos de la investigación, método y criterios éticos. Se pidió que firmaran un consentimiento informado aceptando participar, donde se aseguraba el anonimato, el deber de confidencialidad y el derecho a abandonar la investigación.

En la siguiente tabla se muestran las características definitorias de los casos seleccionados para este artículo. 


\begin{tabular}{|c|c|c|c|c|}
\hline Caso & $\begin{array}{c}\text { Nivel socio- } \\
\text { económico }\end{array}$ & $\begin{array}{l}\text { Zona de } \\
\text { residencia }\end{array}$ & $\begin{array}{c}\text { Actividades } \\
\text { extraescolares }\end{array}$ & $\begin{array}{c}\text { Dispositivos } \\
\text { propios }\end{array}$ \\
\hline $\begin{array}{l}\text { Antón (An) } \\
\text { (mellizo) }\end{array}$ & Medio & Rural & Inglés & $\begin{array}{c}\text { Táblet y } \\
\text { PC_escuela }\end{array}$ \\
\hline $\begin{array}{l}\text { Alfonso (Al) } \\
\text { (mellizo) }\end{array}$ & Medio & Rural & Inglés & $\begin{array}{c}\text { Táblet y } \\
\text { PC_escuela }\end{array}$ \\
\hline $\begin{array}{l}\text { Lucía (Lu) } \\
\text { (gemela) }\end{array}$ & Alto & Urbanización & $\begin{array}{l}\text { Música y } \\
\text { atletismo }\end{array}$ & $\begin{array}{l}\text { Wii compartida } \\
\text { y Nintendo } \\
\text { 3DS }\end{array}$ \\
\hline $\begin{array}{l}\text { Catarina }(\mathrm{Ca}) \\
\text { (gemela) }\end{array}$ & Alto & Urbanización & $\begin{array}{l}\text { Música y } \\
\text { atletismo }\end{array}$ & $\begin{array}{l}\text { Wii compartida } \\
\text { y Nintendo } \\
\text { 3DS }\end{array}$ \\
\hline Elisa (El) & Medio & Semiurbano & Tenis & Móvil y táblet \\
\hline
\end{tabular}

Tabla 1. Casos seleccionados para la fase cualitativa

Las técnicas de recogida de datos se basaron en estrategias que permitieron acercarse a los sujetos y profundizar en las prácticas de estos en la red: entrevistas en profundidad, observación participante, diarios de los niños y niñas, análisis documental y diario de campo. Se realizaron tres entrevistas en profundidad a cada uno de los participantes (niños y niñas), dos entrevistas a las familias, una a la tutora o tutor del centro educativo y, en algunos casos, también se entrevistó a una amiga cercana.

Las entrevistas fueron grabadas en vídeo y audio y transcritas para su análisis. La información (textual) recogida por medio de las otras estrategias se digitalizó. El corpus de datos fue incorporado al software cualitativo Atlas.ti (v.7) para su análisis, a través del método comparativo constante (Glaser y Strauss, 1967). En la fase de codificación abierta se codificaron los fragmentos de información a través de categorías emergentes de los propios datos, a la vez que se atendió a la literatura sobre el tema. En la fase de codificación axial se establecieron relaciones entre las categorías, aumentando la densidad de las categorías centrales. Finalmente, en la fase de codificación selectiva se realizaron redes que permitieron construir la teoría.

\subsection{Prueba de evaluación de la Competencia Digital}

La segunda fase, cuantitativa, consistió en la administración de la prueba de evaluación de la competencia digital de los estudiantes de educación obligatoria (ECODIES). Una prueba que consta de 108 ítems y se estructura en cinco bloques, que se corresponden con las cinco áreas o dimensiones de la Competencia Digital del marco del Proyecto DigComp. Se realizan cuestiones sobre conocimientos (32), habilidades, destrezas y prácticas (46), y actitudes (30) en torno a las subcompetencias que configuran cada una de las áreas.

El primer bloque (Área 1. Información) contiene seis cuestiones sobre conocimientos acerca de la búsqueda, evaluación y almacenamiento de la información; seis ítems de 
capacidad y seis referidos a actitudes. El segundo bloque (Área 2. Comunicación) incluye ocho cuestiones sobre conocimientos acerca de la interacción con tecnología, compartir información, participar y colaborar en la red, cuestiones de netiqueta y de gestión de la identidad digital; diez ítems sobre habilidades prácticas en torno a estas cuestiones; y seis referidos a actitudes. El bloque tres (Área 3. Creación de contenido) está compuesto por cinco preguntas referidas al desarrollo de contenido digital, licencias y derechos de autor, y lenguaje de programación; once cuestiones que indagan en las capacidades y habilidades en torno a estas temáticas; y seis referidas a actitudes. El bloque cuatro (Área 4. Seguridad) incluye seis preguntas acerca de conocimientos sobre protección de dispositivos, datos personales, salud y entorno; diez interrogantes sobre capacidades ante estas cuestiones; y seis ítems referidos a actitudes. Finalmente, el bloque cinco (Área 5. Resolución de problemas) incorpora siete cuestiones en torno a conocimientos sobre resolución de problemas técnicos, identificación de necesidades, uso creativo de la tecnología e identificación de lagunas en la propia competencia digital; nueve interrogantes referidos a habilidades y destrezas en estas cuestiones; y seis ítems referidos a actitudes. La puntuación máxima para cada área es 20.

La prueba, validada a través de expertos, obtiene un coeficiente Alpha de Cronbach de 0,89 , que indica una buena consistencia interna y fiabilidad de la prueba (George y Mallery, 2003). En concreto, para la dimensión seguridad el coeficiente Alpha de Cronbach se encuentra en un $75 \%(0,755)$, un nivel aceptable según George y Mallery (2003).

Para la selección de la muestra, alumnado de $6^{\circ}$ curso de Educación Primaria de centros públicos de Galicia, se utilizó un muestreo estratificado, seleccionando aulas y centros completos en función de diferentes variables (provincia, pertenencia a e-dixgal ${ }^{5}$ y densidad poblacional de la zona). Participaron en la prueba 764 niños y niñas. Para este artículo, centrado en la perspectiva de género y la dimensión seguridad, se realiza una primera limpieza de los datos eliminando los casos con valores perdidos en la variable género, quedando $n=544$ escolares. Con estos casos se realiza una nueva limpieza de valores perdidos atendiendo a las cuestiones relativas a actitudes sobre la seguridad digital, contando finalmente con $n=486$ sujetos, 249 niñas y 237 niños.

Los datos fueron analizados con el paquete estadístico IMB SPSS Statistics (v. 22). Se realizaron análisis de estadísticos descriptivos y pruebas de contraste de hipótesis, en concreto la Prueba T de comparación de medias para muestras independientes, empleando el género como variable de agrupación.

\section{Resultados}

Las niñas y niños partícipes en el proyecto se apropian de las tecnologías de formas distintas, desarrollando además habilidades, competencias y fortalezas diferentes en el marco de sus redes personales de aprendizaje, en los intercambios con sus grupos de iguales, en el entorno familiar y, en menor medida, en el contexto escolar. El tipo de contenidos que consumen unas y otros, los dispositivos que eligen, así como sus estrategias de comunicación y juego en el campo digital varían en función de diferentes variables, entre las que destaca el género al que pertenecen.

Los resultados del estudio muestran ciertas tendencias en función del género. Para exponer los mismos se presentan en primer lugar, de forma genérica, los hallazgos en

\footnotetext{
${ }^{5}$ Proyecto Educación Digital: Política de implantación del libro de texto digital en Galicia.
} 
torno al desarrollo de la dimensión seguridad de la competencia digital. A continuación se pone el foco en los usos y formas que contemplan y emplean niñas y niños para compartir y colaborar en la red. Finalmente se exponen los resultados referidos a cuestiones de privacidad y seguridad en la red.

\subsection{Desarrollo de la dimensión seguridad}

Los resultados de la prueba ECODIES, empleada en este estudio, muestran que las niñas destacan en todas las dimensiones con valores medios superiores a los obtenidos por los niños (Figura 1). Con mayor énfasis en la dimensión seguridad, aquella en la que se obtienen valores más altos y una diferencia significativa entre la puntuación media obtenida por niñas $(13,63)$ y niños $(12,66)$; seguida de la dimensión comunicación, que incluye también cuestiones relativas a la gestión de la propia identidad digital. Donde las niñas obtienen una puntuación media de 13,17 sobre 20, y ellos de 12,24.

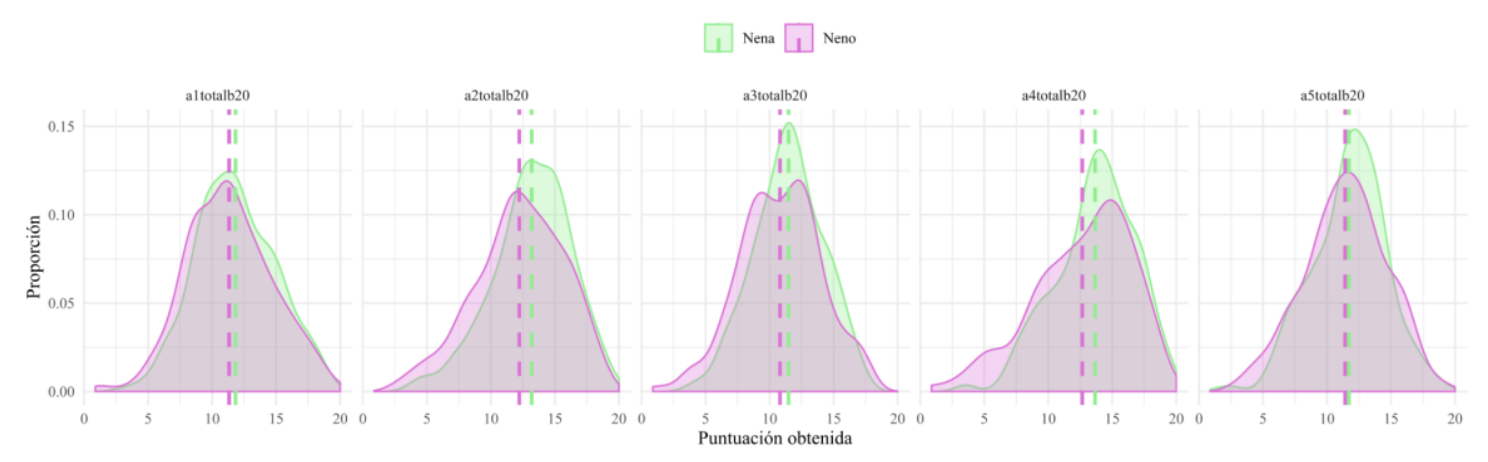

Figura 1. Distribución según las cinco dimensiones de la competencia digital y el sexo

La realidad de los casos de estudio, sin embargo, revela que el área seguridad es precisamente la de menor presencia en el desarrollo de la competencia digital de Lucía, Catarina, Alfonso y Antón. Tanto desde el punto de vista declarativo como desde la práctica no ocupa una posición relevante en la actividad de estas niñas y niños con las tecnologías. En el caso de Elisa, en quien sí se observa la presencia de actitudes proclives a la seguridad en la red, se detectan incoherencias discursivas en la práctica con tecnologías que la identifican con sus iguales partícipes en la investigación.

Se constata, por ejemplo, que prácticas básicas como la realización de copias periódicas de seguridad de los archivos que producen en el colegio, no se contemplan por parte de Caterina y Lucía. Se pone de manifiesto que no son conscientes de la importancia de llevarlas a cabo, probablemente porque tampoco se les ha insistido en esta necesidad.

Entrevistadora: Pero, y ¿soléis guardarlo en el pen o normalmente no...?

Catarina: No, no lo guardamos casi nunca. [...] porque no teníamos pensado tampoco, que íbamos a cambiar de ordenador. (Ca_2)

Los resultados de la prueba muestran un alto grado de concienciación con las oportunidades y riesgos de Internet. Las medias de las puntuaciones relativas a las actitudes sobre el uso seguro de la tecnología y la red superan el 4 de 5 . Una negociación entre dos polos que se constata también en las actitudes manifestadas en el estudio de 
casos, a pesar de coexistir con prácticas no consecuentes, pues parecen carecer de estrategias o mecanismos que les permitan articular un uso seguro de Internet.

\subsection{Compartir, colaborar y relacionarse en la red}

Los datos de la prueba muestran los altos valores de concienciación en torno a los cuidados al compartir la información de los otros/as en Internet, la gestión de las solicitudes de desconocidos/as y el comportamiento en la red (Figura 2).

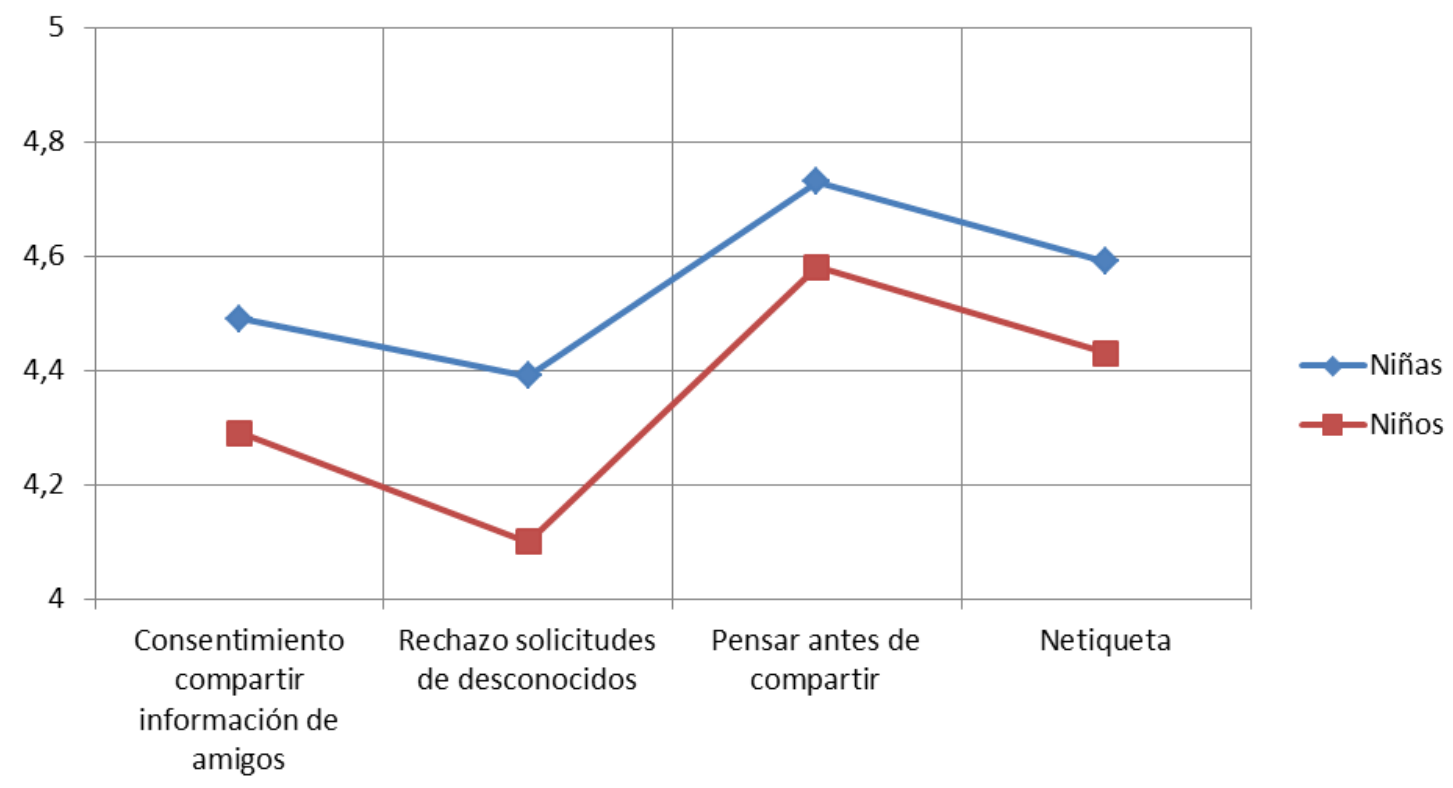

Figura 2. Puntuaciones de Actitud respecto al comportamiento en la red (1-5)

Las puntuaciones revelan la alta concienciación sobre la necesidad de actuar y comportarse de forma adecuada en la red. Una predisposición mayor en ellas, que dista, en cierta medida, de las prácticas reales del día a día de las niñas y niños de 11 y 12 años. Catarina y Lucía no poseen cuenta en ninguna red social, aunque las conocen a través de sus compañeras del colegio y de otros círculos de amistades. De hecho, una compañera entrevistada manifiesta que cuando quedan fuera del colegio, suelen pedirle el móvil.

Entrevistadora: Sí, ¿y tú estás con el móvil o...?

Elisa: Yo no, están ellas.

Entrevistadora: Vale, entonces eso, ellas están con tu móvil, ¿y qué hacen con él móvil?

Elisa: Pues mira... No sé, de todo. (El_3)

En cambio, ambas muestran una actitud especialmente crítica hacia estas redes, así como hacia el uso de teléfonos móviles y de aplicaciones como el Whatsapp. Quizás esta actitud se explica, no tanto por un elevado desarrollo del área seguridad de la CD, como por la influencia del contexto familiar (padre y madre reacios a permitirles el acceso a esos entornos o dispositivos) e incluso escolar (donde se han impulsado algunas iniciativas informativas acerca del peligro de las redes sociales). Esto se evidencia también con Elisa, cuya conciencia en torno a la seguridad versa sobre aquellas prácticas ligadas a la configuración y gestión de su identidad digital; especialmente la difusión de su imagen y la delimitación de las y los conocidos y desconocidos entre sus seguidores/as en las redes; 
respaldándose en una preocupación parental por proteger a su hija de los peligros, que su madre y su padre expresan a través de los conceptos "bullying" y "sexualización".

Elisa tiene un discurso sólido acerca de las relaciones con personas desconocidas en la red, e incluso muestra cómo ha gestionado en alguna ocasión situaciones consideradas de riesgo, que semejan ser frecuentes.

Elisa: Ah sí, mira, este, es el tío que te dije que me puso "Hola, hola, ¿quién eres?, Una persona ¿Y tú?, Un ser humano.... Y lo bloqueé, ¿no ves? Está aquí(El_3).

En cambio, considera conocidas a todas aquellas personas con las que tenga algún vínculo y le resulten interesantes, observándose que en sus redes abundan entre las/os seguidas/os y seguidoras/es personas que identifica con aquellas otras de su colegio que han pasado al instituto, pero a quienes no ha visto nunca. El instituto es reconocido, por consiguiente, como un elemento de unión que emplea como identificador de que esas personas son reales e iguales y que no suponen a priori un peligro. En esta línea, Alfonso y Antón desarrollan también estrategias y habilidades en la interacción con extraños en la red, especialmente en torno a videojuegos o contenidos mediáticos: parecen tener una mirada diferenciada entre aquellos desconocidos vinculados a intereses comunes, con los que sí se comunican y en los que no perciben peligro alguno - por ejemplo, a través de los chats de juegos: "no conozco a la gente, pero me cae bien" (An_2) - y aquellos con los que aparentemente no comparten un interés común, lo que les otorga rango de "extraño". A pesar de que estas prácticas de contactos comunicativos con desconocidos son consideradas socialmente como un riesgo (alentado por el discurso de alarma social, que explicaría de alguna manera las altas puntuaciones de las actitudes a este respecto en la prueba, especialmente en las niñas), en este hogar es entendida, sin embargo, como una oportunidad de expresión y socialización.

En los casos de las niñas esta preocupación trasciende: la familia de Catarina y Lucía se muestra crítica frente al uso no académico de la tecnología; y la de Elisa, amplía el control parental cuestionando su privacidad, de modo que aquello que suceda en entornos digitales o a través de estas herramientas debe quedar expuesto para sus progenitores.

Madre: intentamos ver todos los mensajes. Tenemos con ella un acuerdo de que no puede borrar mensajes, porque además te das cuenta de la continuidad y de que quedan conversaciones (incompletas)... y que nosotros tenemos que saber las contraseñas y poder acceder a todo lo que tiene en el móvil (Md_El_1).

Ambos atajan su preocupación acerca de la exposición de su hija a aquellos riesgos que perciben en la red a través de la prohibición de difusión de vídeos e imágenes en las que se vea con claridad a la menor. A esto se añade el veto al contacto con los denominados "desconocidos", un concepto ambiguo que se desdibuja en las largas redes de relaciones entre las y los iguales. Ante estas normas, Elisa muestra una actitud semejante a la evidenciada por las Catarina y Lucía, aceptando y reproduciendo el discurso de sus padres, afirmando que aprueba que su madre y su padre revisen toda su actividad en las redes cuando se le pregunta qué le parecen estas normas: Casi bien...porque imagínate, por ejemplo, que tengo acoso y no se lo quería decir a ellos, y hablo con una persona pues ellos lo ven y pueden pararlo (El_3). 
Mientras Elisa amplía el campo de conocidos a partir de indicadores que acepta como válidos, por considerarlos reales fuera de la red; Alfonso y Antón lo hacen a partir de su percepción, subjetiva, sobre las personas concretas con las que se relacionan en la red.

Los casos coinciden con los resultados obtenidos en la prueba en lo que respecta a las actitudes y concienciación, más alta por parte de las niñas con diferencias significativas entre los valores medios de ambos géneros ( $\mathrm{p}<0.002)$; especialmente en la respuesta a rechazar solicitudes de desconocidos en las redes sociales. En este sentido, las contradicciones observadas entre las prácticas y el discurso sugieren una reproducción acrítica del discurso parental y no un cuestionamiento crítico acerca de la identidad en la red y las posibilidades y riesgos de las relaciones con personas desconocidas.

\subsection{Privacidad y seguridad en la red}

Los resultados evidencian, además, otras cuestiones relativas a la privacidad y uso seguro de las tecnologías, donde se mantienen las puntuaciones medias altas, como la conciencia sobre las consecuencias de subir información personal a la red, el poder de adicción de las tecnologías o el valor de respeto al medioambiente. Ante todas estas cuestiones las niñas muestran una actitud de mayor consciencia y sensibilización.

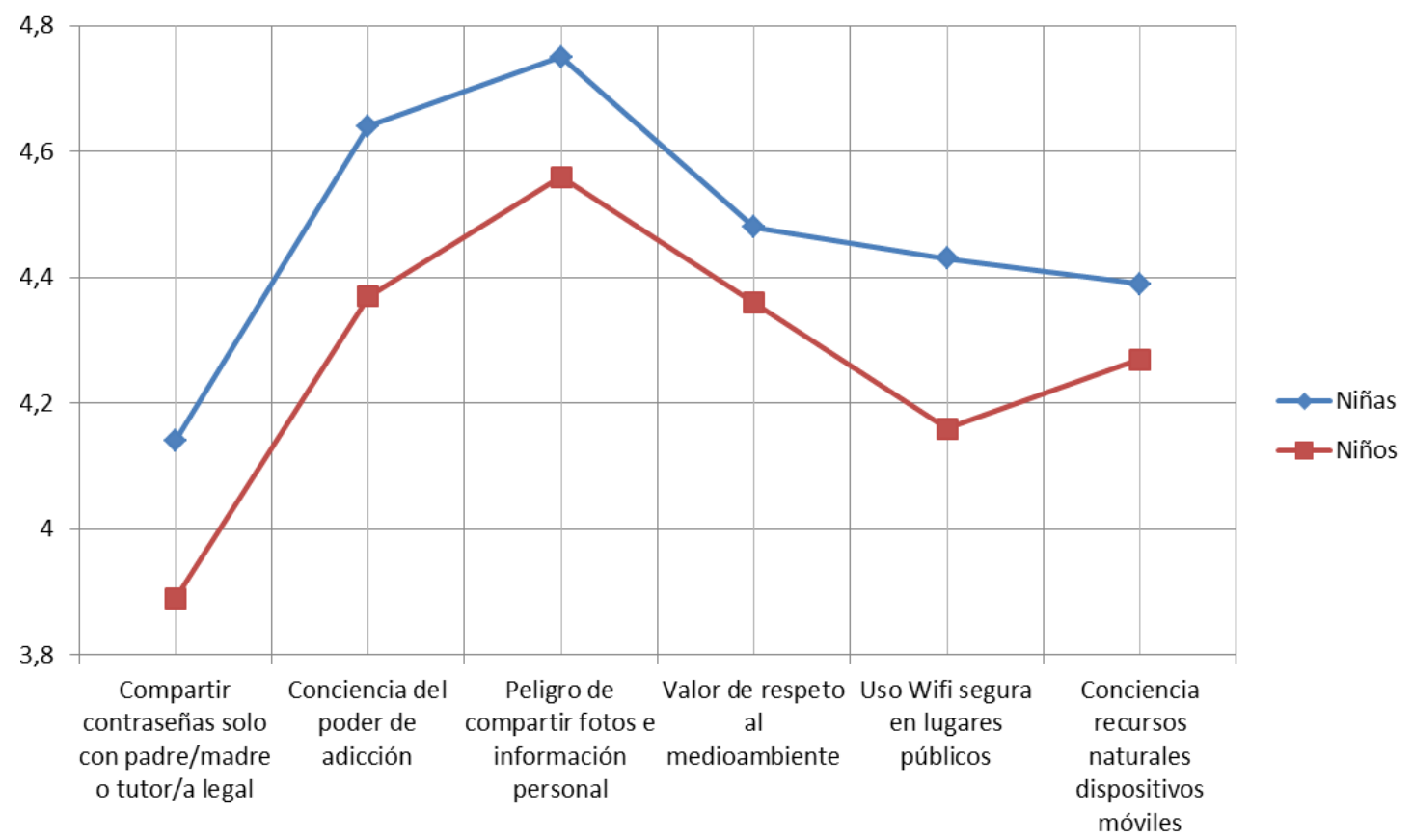

Figura 3. Puntuaciones de Actitud de la dimensión Seguridad (1-5)

La puntuación media más baja, para ellas $(4,14)$ y ellos $(3,89)$, refiere a actitudes sobre compartir sus contraseñas. A este respecto, Elisa señala actos imprudentes de algunos de sus compañeros en Internet, como la publicación y difusión de la contraseña de sus redes sociales o correo electrónico. En cambio, ella adopta prácticas como el guardado de contraseñas y acostumbra a anotarlas en diferentes lugares (digitales y analógicos) para no olvidarlas. En torno a esto surgen evidencias de no ser una preocupación de urgencia en el hogar y en la escuela; por lo que no se invierte esfuerzo en establecer unas pautas de uso claras y que faciliten el aprendizaje de las medidas más adecuadas. De hecho, 
Lucía llega a dudar a la hora de escribir su nombre de usuaria para acceder a su correo electrónico y, en ocasiones, demuestra no tener tampoco claras sus contraseñas. De todos modos, Catarina y Lucía sí muestran cierto conocimiento respecto de la importancia de las mismas, aún con limitaciones, asegurando manejar una misma contraseña para varias aplicaciones, pero siendo en todo caso conscientes de la importancia de no darla a conocer más allá de su hermana y su maestra. Ambas inciden también en que esta es una cuestión de la que no han sido informadas en la escuela, donde "no se habla" de este tema. No se transmiten pues, atendiendo a lo que nos cuentan las niñas, unas pautas de uso correctas de medidas de seguridad que puedan ser conocidas y trasladadas a otros contextos. Por su parte, tanto Antón como Alfonso cambian con frecuencia las contraseñas en sus cuentas en redes sociales, pero no tanto por una cuestión de seguridad, sino porque son proclives a olvidarlas.

Se evidencia en el discurso de concienciación de estas y estos preadolescentes la influencia del marco familiar. La principal preocupación y aquella que es compartida por todas las familias objeto de estudio, versa sobre la variable espacio-tiempo: el control se establece fundamentalmente en relación a cuánto tiempo y cuándo se utilizan los dispositivos. Como sucede en el caso de Antón y Alfonso, donde la madre ha incorporado una herramienta de control parental, que sustantivamente se ocupa del tiempo que los niños ocupan con los dispositivos y se han establecido unas normas (que muchas veces no se cumplen) sobre el uso de la tableta y los videojuegos, solo los fines de semana. $\mathrm{Su}$ madre asegura tener activado el control parental "básicamente para que no estén conectados todo el día" (Md_AlAn_1).

En disonancia, Catarina y Lucía apenas utilizan las TIC para comunicarse o interactuar con otros niños o niñas de su edad o de sus círculos de amistades, y mucho menos con personas desconocidas en la red. La comunicación se lleva a cabo en el marco del contexto de la familia extensa o para cuestiones ligadas a las tareas escolares: enviar trabajos a la profesora, preguntar a las compañeras por trabajos escolares, etc. Este comportamiento se observa también en las actitudes referidas a la gestión de la identidad digital que implican una reputación online y huella digital.

La puntuación media en la prueba de la actitud hacia los peligros de compartir información personal y familiar en la red es la más alta en el caso de las niñas $(4,75$ de 5). Donde ellos también puntúan con una media destacada $(4,56)$. En este sentido, los casos de Lucía, Catarina y Elisa muestran prácticas en consonancia con esta actitud de precaución y cautela en la participación en la red. En el caso de las primeras cabe destacar que muestran un escaso interés por compartir sus producciones: imágenes, vídeos, ediciones de fotos realizadas con aplicaciones como Snapchat, etc. Ellas argumentan que, simplemente, no tienen a quién enviárselas; pero es posible que no conozcan la manera de hacerlo, que quizás se trate de una actitud precavida y propia de su competencia de seguridad, o bien que tal vez respondan a un deseo o norma de sus progenitores, que no desean que compartan imágenes por el peligro potencial que podría traer consigo. En ocasiones, pues, Catarina y Lucía emplean la aplicación Snapchat (inicialmente instalada por su prima en el iPad) para crear contenido y como herramienta de edición de imágenes (especialmente fotografías propias, que transforman por diversión); pero no la usan para publicar, hacer visible o compartir sus producciones, rechazando una de las funcionalidades más características de esta aplicación. 
Elisa, a pesar de tener un papel más activo en las redes, coincide con las hermanas gemelas en el uso que realiza de redes sociales como Snapchat y Musica.ly como herramientas de edición de imagen y creación de contenido, siempre sin compartirlo. Esta actuación conecta con las órdenes de sus padres, que ven en la exposición de imagen un riesgo de sexualización de la menor y en la creación de vídeos en Musica.ly una actividad que pueda servir de argumento para la ridiculización y el bullying hacia su hija a través de la red. En el caso de Elisa, a pesar de ser ella quien afirma no querer hacerlo, es una fiel seguidora de las personas que crean este tipo de contenido con las que interactúa a través del like; de las apps y nuevas plataformas que surgen para la edición; y emplea la creación de estos como una actividad que ocupa su tiempo libre cuando su madre y padre le dejan usar el teléfono móvil.

Por su parte, Alfonso y Antón invierten el tiempo de ocio en el que disponen de tecnologías en los videojuegos, alrededor de los cuales generan relaciones con otras personas. No comparten fotos personales ni propias en perfiles públicos de Facebook, Twitter o Instagram; pero a diferencia de las niñas partícipes, tampoco dedican tiempo a su creación y no muestran reticencias a la hora de compartir fotos que encuentran en la red, sin conocer ni respetar los derechos de autoría. A pesar de que ellos también muestran conciencia acerca de la necesidad de proteger su información personal, este discurso se presenta de forma débil. En el caso de Alfonso, una mala práctica en su perfil privado de Instagram le llevó a tener problemas con una foto en la que figuraba información personal de una tercera persona. Este incidente semejaba preocuparle y lo recordaba con frecuencia cuando abría su perfil privado en la plataforma.

En este caso, se observa un vínculo con el marco familiar de Alfonso y Antón, donde la competencia relativa a seguridad de los aparatos está débilmente estructurada, con escasos conocimientos, pues el entusiasmo por descargar contenidos cobra más significado que el hecho de prever las consecuencias que esto pueda tener. Es su madre quien asume un rol principal en la educación en redes sociales de sus hijos. Aunque no es conocedora de todas las redes que tienen, insiste en las cuestiones que considera relevantes cuando se crea un perfil en alguna de estas: "hay que tener cuidado a la hora de subir unas fotos, que esa información se puede... se lo vas explicando" ( $\mathrm{Md} \_\mathrm{AlAn}$ 2). Sin embargo, en los casos de Lucía, Catarina y Elisa su referente tecnológico en el hogar es, si duda, su padre; lo que vendría a coincidir con los resultados de algunos estudios (Yuen, Lau, Parque, Lau y Chan, 2016) que inciden en la asunción o atribución prioritaria del rol de orientadores por parte de los progenitores masculinos por encima de las madres, que suelen ser relegadas a un plano más secundario.

El discurso entorno a la seguridad adquiere, por tanto, tintes diferenciados entre los dos niños y las tres niñas. En el caso de Alfonso y Antón, el discurso familiar está ligado a la limitación del uso de dispositivos, la precaución con las adicciones al juego o las redes y la repercusión de compartir datos privados en la red. Lo cual contrasta con el caso de Elisa, donde las precauciones entorno a la proyección de la propia imagen, la configuración de la identidad digital y la permanencia de los datos, versan sobre la sexualización de la menor, la pedofilia y el bullying por parte de sus iguales en la red. Aun a pesar de que, en el marco familiar de Elisa, el discurso entorno a la dimensión de seguridad es amplio, su madre y su padre manifiestan no saber cómo actuar para proteger a su hija de un mundo al que quieren que tenga acceso, en reconocimiento de sus potencialidades, pero que asumen como altamente peligroso. 


\section{Conclusiones}

Las tecnologías digitales son parte del tejido social; y dado que estas y la sociedad se producen mutuamente, expresan las relaciones sociales en las que están integradas (Bonder, 2008; Ficoseco, 2016). Esta reproducción de las estructuras de poder es fácilmente visible en la ausencia de mujeres en el relato tecnológico o la expresión binaria y estereotipada de la misma (Haraway, 2006; Macharia, 2015), por lo que estos entornos propician diferentes oportunidades de participación y aprendizaje en función de la socialización de género.

Los datos de la prueba contrastan a priori con este planteamiento, de acuerdo con el cual existe una brecha digital de género que afecta intensamente a mujeres y niñas (Castaño, Martín y Luis, 2011; Comisión Europea, 2018; Espinar y González, 2010; Flores-Lueg y Roig-Vila, 2017; García, Gros y Escofet, 2012; Mhlana y Krauss, 2017; Vázquez y Castaño, 2011). La prueba se ha realizado en el contexto escolar, donde el uso de las TIC se aproxima en mayor medida al desempeñado por las niñas (correo electrónico, comunicación...) que al de los niños (mayormente vinculadas a los videojuegos, participación en comunidades que versan sobre estos mismos intereses, etc.); al contemplar los casos de estudio, los datos de la prueba en la dimensión seguridad dan luz sobre ciertos aspectos que deben ser analizados desde una perspectiva de género.

En los casos se observa una consonancia con los resultados de la prueba en lo que compete a la existencia de oportunidades y riesgos en el uso de nuevas tecnologías, así como la necesidad de desempeñar una práctica segura (Gallego-Arrufat et al., 2019 y AlonsoFerreiro, 2016). Las niñas adoptan prácticas más prudentes que las de los niños, pero se observa que esta prudencia no versa sobre el conocimiento y la reflexión crítica, sino que parte de la reproducción de un discurso parental.

La perspectiva parental se apoya en el pánico mediático: las preocupaciones principales se refieren a los tiempos y espacios de uso, las adicciones a la tecnología y la exposición de la imagen y datos personales que identifiquen a sus hijos en un contexto espaciotemporal. La preocupación parental principal, por consiguiente, es proteger a sus hijas/os (Buckingham, 2002) en el mundo físico. Por ello, mientras la madre de Antón y Alfonso incide en los tiempos de uso y la información difundida; las familias de las niñas suman a estas preocupaciones otras condicionadas por el género de sus hijas y la violencia a la que este las expone a ellas en mayor medida: la sexualización o el acoso (Charteris, Gregory y Masters, 2018).

El discurso que reciben los casos entorno a la seguridad es más protector y restrictivo en el caso de las niñas, a quienes se les niega o limita la configuración de su identidad en la red y la creación de vínculos con personas desconocidas con las que puedan mantener intereses en común. Un discurso menos sólido y preocupado es el que caracteriza a los niños. Lo cual podría mantener relación con los valores obtenidos en la prueba, donde las niñas evidencian un discurso acerca de la competencia digital en la dimensión seguridad más alta que los niños.

A su vez, son ellas quienes muestran una mayor sumisión a las órdenes familiares y quienes argumentan reiteradamente un sentimiento de miedo a situaciones de bullying, como la compartida por Elisa, o una autopercepción de incompetencia para emplear de forma segura las nuevas tecnologías y minimizar los riesgos, como en el caso de Catarina 
y Lucía. Su práctica segura pasa por la limitación de su actividad, condicionamiento de su privacidad y menor autonomía.

Por otra parte, se evidencian incoherencias entre el discurso y la práctica, tanto en el uso y gestión de contraseñas, como en la creación de redes de amistades en Internet. Si bien las y los preadolescentes poseen un discurso sobre la seguridad que han bebido de las preocupaciones familiares, mediáticas y políticas actuales (Alonso-Fereiro, 2016; Marciales y Cabra, 2011); no poseen estrategias que les permitan articular una práctica segura con las tecnologías: operativizar el discurso.

Una vez que hemos alcanzado y popularizado un discurso acerca de los riesgos de la red y la necesidad de una práctica segura, cabe actuar críticamente ante la reproducción de antiguas prácticas que versan sobre la difusión de discursos del miedo. Es preciso dotar de estrategias al alumnado que permitan la operativización del discurso de seguridad desde la escuela. Esta alfabetización mediática, como han venido defendiendo múltiples autoras y autores, debe plantearse desde una perspectiva de género; pues el pánico mediático y la protección de las menores ante los peligros en la red han propiciado la reproducción de las mismas prácticas que se han articulado tradicionalmente en la sociedad con las mujeres como posibles víctimas de violencia machista: demandarles una precaución restrictiva sin profundizar críticamente en el origen de la violencia.

En contraste con los tintes democráticos con los que se ha presentado la red hasta ahora, los espacios y plataformas donde las niñas y niños interactúan, se relacionan y aprenden parecen no ser el oasis de igualdad que se figuraba. En este contexto, se plantean nuevos interrogantes acerca de cómo las y los preadolescentes construyen su identidad de género en la red y el modo en el que esta construcción influye en la apropiación tecnológica.

\section{Agradecimientos}

Quisiéramos manifestar nuestro más profundo agradecimiento a todos los niños y niñas participantes en la investigación, muy especialmente en este caso a Catarina, Lucía, Antón, Alfonso y Elisa, por mostrar en todo momento una enorme ilusión, compromiso y ganas de aportar lo máximo al estudio. También deseamos trasladar nuestra gratitud a las familias y centros escolares colaboradores en la investigación, por su generosa participación y contribuciones.

Presentación del artículo: 15 de julio de 2019

Fecha de aprobación: 8 de noviembre de 2019

Fecha de publicación: 30 de noviembre de 2019

Alonso-Ferreiro, A. Regueira, U., y Zapico-Barbeito, M.H. (2019). Actitudes de alumnado preadolescente ante la seguridad digital: un análisis desde la perspectiva de género. RED. Revista Educación a Distancia, 61. DOI:

http://dx.doi.org/10.6018/red/61/02

\section{Financiación}

El Proyecto "Competencia digital en estudiantes de educación obligatoria. Entornos sociofamiliares, procesos de apropiación y propuestas de e-inclusión” (CDEPI) es una investigación financiada por el Ministerio de Economía y Competitividad (Ref.: EDU2015-67975-C3-1-P) y por el Fondo Europeo de Desarrollo Regional (FEDER). 


\section{Referencias bibliográficas}

Alonso-Ferreiro, A. (2016). Competencia Digital y Escuela. Estudio de Caso Etnográfico en dos CEIP de Galicia (Universidade de Santiago de Compostela). Recuperado de https://www.educacion.gob.es/teseo/mostrarSeleccion.do\#

Alonso-Ruido, P., Rodríguez-Castro, Y., Lameiras-Fernández, M. y Carrera-Fernández, $\mathrm{M}^{\mathrm{a}}$ V. (2015). Hábitos de uso en las redes sociales de los y las adolescentes: análisis de género. Revista de Estudios e Investigación en Psicología y Educación, Vol. Extr., No. 13, A13-055. Recuperado de http://revistas.udc.es/index.php/reipe/article/view/317

Annansingh, F. y Veli, T. (2016). An investigation into risks awareness and e-safety needs of children on the internet. Interactive Technology and Smart Education, 13(2), 147165. Recuperado de https://doi.org/10.1108/ITSE-09-2015-0029

Belloch, MacC., Gargallo, B. y Suárez, J. (2003). La división digital en el proceso de integración de las NTIC en la educación. Diferencias de género entre alumnos de ESO de la Comunidad Valenciana. Teoría de la educación: educación y cultura en la sociedad de la información, 4 [versión electrónica]. Recuperado de https://gredos.usal.es/handle/10366/56461 ?locale-attribute=en

Bonder, G. (2008). Juventud, Género y TIC: imaginarios en la construcción de la sociedad de la información en América Latina. ARBOR Ciencia, Pensamiento y Cultura, 733, 917-934. Recuperado http://arbor.revistas.csic.es/index.php/arbor/article/view/234

Broos, A. (2005). Gender and Information and Communication Technologies (ICT) Anxiety: Male Self-Assurance and Female Hesitation. CyberPsychology Behavior, vol. $8(1), 21-31 . \quad$ Recuperado de https://www.liebertpub.com/doi/10.1089/cpb.2005.8.21

Buckingham, D. (2002). Crecer en la era de los medios electrónicos. Madrid: Morata.

Byrne, J., Kardefelt-Winther, D., Livingstone, S. y Stoilova, M. (2016). Global Kids Online research synthesis, 2015-2016. UNICEF Office of Research-Innocentiand London School of Economics and Political Science. Recuperado de www.globalkidsonline.net/synthesis

Carretero, S., Vuorikari, R. y Punie, Y. (2017). The Digital Competence Framework for Citizens. With eight proficiency levels and examples of use (N. ${ }^{\circ}$ EUR $\left.28558 \mathrm{EN}\right)$. Recuperado de Joint Research Centre website: http://publications.jrc.ec.europa.eu/repository/bitstream/JRC106281/webdigcomp2.1pdf_(online).pdf

Castaño, C., Martín, J. y Luis, J. (2011). La brecha digital de género en España y Europa: medición con indicadores compuestos. Revista Española de Investigaciones Sociológicas (REIS), 136, 127-140(14). Recuperado de http://www.reis.cis.es/REIS/PDF/REIS_136_061318594338821.pdf 
Charteris, J., Gregory, S. y Masters, Y. (2018). 'Snapchat', youth subjectivities and sexuality: disappearing media and the discourse of youth innocence. Gender and Education, 30(2), 205-221. Recuperado de https://www.tandfonline.com/doi/abs/10.1080/09540253.2016.1188198

Comisión Europea (2018). The underlying causes of the digital gender gap and possible solutions for enhanced digital inclusion of women and girls. Policy Department for Citizens' Rights and Constitutional Affairs: Women's rights \& Gender equality. Recuperado de http://www.europarl.europa.eu/supporting-analyses

Creswell, J. W., y Plano Clark, V. L. (2007). Designing and con-ducting Mixed Methods research. Thousand Oaks, CA: Sage. doi:10.1177/1558689807306132

Dmitrow-Devold, K. (2011). Norwegian Girls in Mainstream Blogging Performed Blogging Selves, Experienced Digital Competences, Gendered Discourses. Doctoral dissertation. Inland Norway University of Applied Sciences. Recuperado de https://pdfs.semanticscholar.org/a69d/cd90de655bd9d071c81dfb782d8cd1672e64.p df

Dmitrow-Devold, K. (2017). What Matters to the Girls? Norwegian Girls' Experiences of Digital Competences in Mainstream Blogging. Young, 25(2), 190-207. Recuperado de https://journals.sagepub.com/doi/abs/10.1177/1103308816673496

Escofet, A. y Rubio, M.J. (2007). La brecha digital: género y juegos de ordenador. Revista Electrónica Iberoamericana sobre Calidad, Eficacia y Cambio en Educación, 5(1), 63-77. Recuperado de https://repositorio.uam.es/handle/10486/660876

ESSIE. (2013). Survey of schools. ICT in Education. Bechmarking Acces, Use and Attitudes to Technology in Europe's Schools. Final Study Report. Recuperado de Comisión Europea website: https://ec.europa.eu/digital-agenda/sites/digitalagenda/files/Spain\%20country\%20profile.pdf

Espinar, E. y González, Ma J. (2010). Jóvenes en las redes sociales virtuales. Un análisis exploratorio de las diferencias de género. Feminismo/s, 14, 87-106. Recuperado de http://rua.ua.es/dspace/handle/10045/13302

Estébanez, I. y Vázquez, N. (2013). La desigualdad de género y el sexismo en las redes sociales. Una aproximación cualitativa al uso que hacen de las redes sociales las y los jóvenes de la CAPV. Victoria-Gasteiz: Servicio Central de Publicaciones del Gobierno Vasco. Recuperado de https://www.euskadi.eus/contenidos/noticia/liburua_sexismoa_gazteak_7/es_def/ad juntos/sexismo_gizarte_sareetan_c.pdf

EU Kids Online (2014). EU Kids Online: findings, methods, recommendations (deliverable D1.6). London, UK. Recuperado de: http://eprints.lse.ac.uk/60512/.

Fernández-Montalvo, J., Peñalva, A. y Irazabal, I. (2015). Hábitos de uso y conductas de riesgo en Internet en la preadolescencia. Comunicar: Revista Científica de Comunicación y Educación, 22(44), 113-121. Recuperado de https://www.revistacomunicar.com/index.php?contenido=detalles\&numero=44\&art iculo $=44-2015-12$ 
Ferrari, A. (2013). DIGCOMP a framework for developing and understanding digital competence in Europe. Recuperado de http://ftp.jrc.es/EURdoc/JRC83167.pdf

Ferrés, J., y Piscitelli, A. (2012). La competencia mediática: propuesta articulada de dimensiones e indicadores. Comunicar, 19(38), 75-82. Recuperado de https://www.revistacomunicar.com/index.php?contenido=detalles\&numero=38\&art iculo=38-2012-10

Ficoseco, V. S. (2016). Mujeres y tecnologías digitales. Antecedentes del campo de los estudios de género para el análisis de esta confluencia. Revista Extraprensa, 9(2), 87$98 . \quad$ Recuperado

de http://www.revistas.usp.br/extraprensa/article/download/107719/114619

Flores-Lueg, C. y Roig-Vila, R. (2017). El género y su incidencia en el nivel de competencia digital autopercibido por estudiantes de Pedagogía. International Journal of Educational Research and Innovation (IJERI), 8, 79-96. Recuperado de http://rua.ua.es/dspace/handle/10045/67516

Gabay-Egozi, L., Shavit, Y., y Yaish, M. (2015). Gender Differences in Fields of Study: The Role of Significant Others and Rational Choice Motivations. European Sociological Review, 31(3), 284-297. Recuperado de https://academic.oup.com/esr/article-abstract/31/3/284/435302

Gallego-Arrufat, M.-J., Torres-Hernández, N., y Pessoa, T. (2019). Competencia de futuros docentes en el área de seguridad digital. Comunicar: Revista Científica de Comunicación y Educación, 27(61), 57-67. Recuperado de https://www.revistacomunicar.com/index.php?contenido=detalles\&numero=61\&art iculo=61-2019-05

García, I., Gros, B. y Escofet, A. (2012). La influencia del género en la cultura digital del estudiantado universitario. Athenea Digital, 12(3), 95-114. Recuperado de https://atheneadigital.net/article/view/v12-n3-garcia-gros-escofet

Garmendia, M. Jiménez, E., Casado, M.A. y Mascheroni, G. (2016). Net Children Go Mobile: Riesgos y oportunidades en internet y el uso de dispositivos móviles entre menores españoles (2010-2015). Madrid: Red.es/Universidad del PaísVasco/Euskal Herriko Unibertsitatea

Gelpi, G.I., Pascoll, N. y Egorov, D. (2019). Sexualidad y redes sociales online: Una experiencia educativa con adolescentes de Montevideo. Revista Iberoamericana de Educación, 80(2, SI), 61-80. Recuperado de https://rieoei.org/RIE/article/view/3230

George, D. y Mallery, P. (2003). Spss for Windows step by step: A Simple Guide and Reference. 11.0 Update (4. ${ }^{\mathrm{a}}$ ed.). Boston: Allyn \& Bacon.

Glaser, B. G., y Strauss, A. L. (1967). The Discovery of Grounded Theory: Strategies for Qualitative Research. New Jersey: Aldine de Gruyter.

Gordo, Á.J. (2006) Jóvenes y cultura Messenger. Tecnología de la información y la comunicación en la sociedad interactiva. Madrid: INJUVE. Recuperado de http://www.injuve.es/observatorio/infotecnologia/jovenes-y-cultura-messenger 
Gui, M. (2007). Formal and substantial Internet information skills: The role of sociodemographic differences on the possession of different components of digital literacy. First Monday, Peer-reviewed journal on the Internet, 12(9). Recuperado 4 de https://firstmonday.org/ojs/index.php/fm/article/view/2009

Gui, M. y Argentin, G. (2011). Digital skills of internet natives: Different forms of digital literacy in a random sample of Northern Italian high school students. New Media \& Society, 13(6), 963-980. Recuperado de https://www.researchgate.net/publication/258173691

Haraway, D. (2006). A Cyborg Manifesto: Science, Technology, and Socialist-Feminism in the Late 20th Century. En: J. Weiss, J. Nolan, J. Hunsinger, P. Trifonas (Eds.), The International Handbook of Virtual Learning Environments. Dordrecht: Springer.

Hargittai, E. (2002). Second-Level Digital Divide: Differences in People's Online Skills. First Monday, Peer-reviewed journal on the Internet, 7(4). Recuperado de https://firstmonday.org/article/view/942/864

Hargittai, E. y Hinnant, A. (2008). Digital Inequality: Differences in Young Adults' Use of the Internet. Communication Research, 35(5), 602-621. Recuperado de https://journals.sagepub.com/doi/10.1177/0093650208321782

Hargittai, E. y Shafer, S. (2006). Differences in Actual and Perceived Online Skills: The Role of Gender. Social Science Quarterly, 87(2), 432-448. Recuperado de https://onlinelibrary.wiley.com/doi/abs/10.1111/j.1540-6237.2006.00389.x

Hatlevik, O.E. y Christophersen, K.-A. (2013). Digital competence at the beginning of upper secondary school: Identifying factors explaining digital inclusion. Computers \& Education, 63, 240-247. Recuperado de https://www.sciencedirect.com/science/article/abs/pii/S0360131512002801

Herring, S. C. y Martinson, A. (2004). Assessing gender authenticity in computermediated language use: Evidence from an identity game. Journal of Language and Social Psychology, $23 \quad$ (4), 424-446. Recuperado de http://ella.slis.indiana.edu/ herring/herring.martinson.2004.pdf

Ito, M. et al. (2009). Hanging out, messing around, and geeking out: Kids living and learning with new media. Cambridge, MA: MIT Press.

Jenkins, H. (2009). Confronting the challenges of participatory culture: media education for the 21 st century. Cambridge, MA: The MIT Press.

Korkmazer, B., De Ridder, S. y Van Bauwel, S. (2019). Reporting on young people, sexuality, and social media: a discourse theoretical análisis. Journal of Youth Studies, 22(4), 1-17. Recuperado de https://www.tandfonline.com/doi/abs/10.1080/13676261.2019.1603365?journalCod $\mathrm{e}=$ cjys 20

Liff, S. y Shepherd, A. (2005), An Evolving Gender Digital Divide? Oxford Internet Institute, Internet Issue Brief, No. 2. Recuperado de http://www.oii.ox.ac.uk/resources/publications/IB2all.pdf 
Livingstone, S. (2014). EU Kids Online: findings, methods, recommendations. London, UK: EU Kids Online.

Livingstone, S., Mascheroni, G. y Staksrud, E. (2015). Developing a framework for researching children's online risks and opportunities in Europe. EU Kids Online, London, UK.

Macharia, S. (2015). Who makes the news? Global Media Monitoring Project. London: WACC. Recuperado de https://bit.ly/2ojGJzk

Mann, A. y DiPrete, T.A. (2013). Trends in gender segregation in the choice of science and engineering majors. Social Science Research, 42(6), 1519-1541. Recuperado de https://doi.org/10.1016/j.ssresearch.2013.07.002

Marciales, V. G. P. y Cabra, T. F. (2011). Internet y pánico moral: revisión de la investigación sobre la interacción de niños y jóvenes con los nuevos medios. Universitas Psychologica, 10 (3), 855-865. Recuperado de https://revistas.javeriana.edu.co/index.php/revPsycho/article/view/841

McLachlan, C., Craig, A. y Coldwell, J. (2010, January). Student perceptions of ICT: a gendered analysis. En Proceedings of the Twelfth Australasian Conference on Computing Education-Volume 103 (pp. 127-136). Australian Computer Society, Inc.

Mhlana, S. y Krauss, K. (2017). The impact of information and communication technology in education: Gender issues. En 2017 International Conference on Infocom Technologies and Unmanned Systems (Trends and Future Directions) (pp. 1-5). Dubai: IEEE. Recuperado de https://ieeexplore.ieee.org/document/8286090

Navarro, M. (2009). La brecha digital de género en España: cambios y persistencias. Feminismo/s, $\quad 14, \quad 183-200 . \quad$ Recuperado de http://rua.ua.es/dspace/handle/10045/13307

Parlamento Europeo (2016). Informe sobre la igualdad de género y el empoderamiento de la mujer en la era digital. Comisión de Derechos de la Mujer e Igualdad de Género. Recuperado de http://www.europarl.europa.eu/doceo/document/A-8-20160048_ES.html?redirect

Pérez-Sinusía, M. y Cassany, D. (2018). Escribir y compartir: prácticas escritas e identidad de los adolescentes en Instagram. Aula de Encuentro, 20(2), 75-94. Recuperado de https://revistaselectronicas.ujaen.es/index.php/ADE/article/view/3907

Reig-Hernández, D. (2012). Disonancia cognitiva y apropiación de las TIC. Telos, 90(1), 9-10. Recuperado de https://telos.fundaciontelefonica.com/

Sadler, P.M., Sonnert, G., Hazari, Z. y Tai, R. (2012). Stability and volatility of STEM career interest in high school: A gender study. Science Education, 96(3), 411-427. Recuperado de https://onlinelibrary.wiley.com/doi/10.1002/sce.21007

Sánchez-Antolín, P., Andrés Viloria, C. y Paredes-Labra, J. (2018). El papel de la familia en el desarrollo de la competencia digital. Análisis de cuatro casos. Digital Education (34), 44-58. Recuperado de http://revistes.ub.edu/index.php/der/article/view/20750 
Sánchez Valle, M., Frutos Torres, B. D. y Vázquez Barrio, T. (2017). La influencia de los padres en la adquisición de habilidades críticas en Internet. Comunicar, 53(25), 103-111. Recuperado https://www.revistacomunicar.com/index.php?contenido=detalles\&numero=53\&art iculo=53-2017-10

Samuelsson, U. (2010). ICT use among 13-year-old Swedish children. Learning, Media and Technology, 35(1), 15-30. Recuperado de https://www.tandfonline.com/doi/abs/10.1080/17439880903560936

Simons, H. (2011). El estudio de caso: Teoría y práctica. Madrid: Ediciones Morata.

Tonucci, F. (2002). Cuando los niños dicen: Basta! Buenos Aires: Editorial Losada.

Toft-Nielsen, C. (2016). Gaming Expertise Doing Gender and Maintaining Social Relationships in the Context of Gamers' Daily Lives. Nordicom Review, 37(SI), 7183. Recuperado de https://www.nordicom.gu.se/sites/default/files/kapitelpdf/10.1515_nor-2016-0024.pdf

Unfried, A., Da Faber, M., Stanhope, D.S. y Wiebe, E. (2015) The Development and Validation of a Measure of Student Attitudes Toward Science, Technology, Engineering, and Math (S-STEM). Journal of Psychoeducational Assessment, 33(7), 622-639. Recuperado de https://journals.sagepub.com/doi/abs/10.1177/0734282915571160

Van Deursen, A. y Van Dijk J. (2009). Improving digital skills for the use of online public information and services. Government Information Quarterly, 26(2), 333-340. Recuperado de https://www.sciencedirect.com/science/article/pii/S0740624X08001524?via\%3Dih $\mathrm{ub}$

Vazquez-Calvo, B. y Regueira, U. (2019). Competencia digital y new literacies de jóvenes preadolescentes: diversidad en la apropiación. En A. Gewerc y E. MartínezPiñeiro (Coords.), Competencia digital y preadolescencia. Los desafíos de la einclusión (pp.139-153). Madrid: Síntesis.

Vázquez, S. y Castaño, C. (2011). La brecha digital de género: prácticas de e-inclusión y razones de la exclusión de las mujeres. Asparkía, Investigació Feminista, 22, 33-49. Recuperado de http://www.e-revistes.uji.es/index.php/asparkia/article/view/596

Vekiri, I. y Chronaki, A. (2008). Gender issues in technology use: Perceived social support, computer self-efficacy and value beliefs, and computer use beyond school. Computers \& Education, 51(3), 1392-1404. Recuperado de https://www.sciencedirect.com/science/article/abs/pii/S0360131508000201

Volman, M., Van Eck, E., Heemskerk, I. y Kuiper, E. (2005). New technologies, new differences. Gender and ethnic differences in pupils' use of ICT in primary and secondary education. Computers \& Education, 45(1), 35-55. Recuperado de https://doi.org/10.1016/j.compedu.2004.03.001 
Vuorikari, R., Punie, Y., Carretero, S., y Van den Brande, L. (2016). DigComp 2.0: The Digital Competence Framework for Citizens. Recuperado de http://ftp.jrc.es/EURdoc/JRC83167.pdf

Wisniewski, T. (2017). The Future Tech Workforce: Breaking Gender Barriers. Illinois: ISACA. Recuperado de http://www.isaca.org/info/2017-women-in-technologysurvey/index.html

Wotanis, L. y McMillan, L. (2014). Performing Gender on YouTube. Feminist Media Studies, 14(6), 912-928. Recuperado de https://www.tandfonline.com/doi/abs/10.1080/14680777.2014.882373

Yuen, A. H., Lau, W. W., Park, J. H., Lau, G. K. y Chan, A. K. (2016). Digital equity and students' home computing: A Hong Kong study. The Asia-Pacific Education Researcher, 25(4), 509-518. Recuperado de https://link.springer.com/article/10.1007/s40299-016-0276-3

Zagami, J., Boden, M., Keane, T., Moreton, B., y Schulz, K. (2015). Girls and computing: Female participation in computing in schools. Australian Educational Computing, 30(2), 1-14. Recuperado de https://journal.acce.edu.au/index.php/AEC/article/view/79 